\title{
Spinal Column Architecture of the Flexible SPP1 Bacteriophage Tail Tube
}

Maximilian Zinke ${ }^{1 \#}$, Katrin A. A. Sachowsky ${ }^{2,3 \#}$, Carl Öster ${ }^{1}$, Sophie Zinn-Justin ${ }^{4}$, Raimond

B.G. Ravelli ${ }^{5}$, Gunnar F. Schröder ${ }^{2,3,6^{*}}$, Michael Habeck ${ }^{7^{*}}$, Adam Lange ${ }^{1,8 *}$

\section{Affiliations:}

${ }^{1}$ Department of Molecular Biophysics, Leibniz-Forschungsinstitut für Molekulare Pharmakologie (FMP), Berlin, Germany.

${ }^{2}$ Institute of Biological Information Processing (IBI-7: Structural Biochemistry), Forschungszentrum Jülich, Jülich, Germany.

${ }^{3}$ Jülich Centre for Structural Biology (JuStruct), Forschungszentrum Jülich, Jülich, Germany.

${ }^{4}$ Institute for Integrative Biology of the Cell (I2BC), CEA, CNRS, Université Paris-Sud, Université Paris-Saclay, Gif-sur-Yvette Cedex, France.

${ }^{5}$ The Maastricht Multimodal Molecular Imaging Institute (M4I), Division of Nanoscopy, Maastricht University, Maastricht, Netherlands.

${ }^{6}$ Physics Department, Heinrich Heine University Düsseldorf, Düsseldorf, Germany.

${ }^{7}$ AG Mikroskopische Bildanalyse, Universitätsklinikum Jena, Jena, Germany.

${ }^{8}$ Institut für Biologie, Humboldt-Universität zu Berlin, Berlin, Germany.

\#M.Z. and K.A.A.S. are equally contributing first authors

*to whom correspondence should be addressed: gu.schroeder@fz-juelich.de (G.F.S.), michael.habeck@med.uni-jena.de (M.H.), or alange@fmp-berlin.de (A.L.) 


\title{
One sentence summary:
}

Integrative structural biology by solid-state NMR and cryo-EM enables structure determination of the flexible tail of the bacteriophage SPP1.

\begin{abstract}
:
Phage therapy has recently regained attention at combating multidrug-resistant bacteria. In 2019, tailed bacteriophages of the Siphoviridae family were engineered to successfully treat a disseminated bacterial infection after all other drugs had failed.(1) This family of phages features a long, flexible, non-contractile tail that has been difficult to characterize structurally. Here, we present the atomic structure of the tail-tube of the bacteriophage SPP1 - a member of this family. Our hybrid structure is based on the integration of structural restraints from solid-state NMR and a density map from cryo-EM. We show that the tail tube protein (TTP) gp17.1 organizes into hexameric rings that are stacked by flexible linker domains and, thus, form a hollow flexible tube with a negatively charged lumen suitable for the transport of DNA.
\end{abstract}

\section{Main Text:}

Tailed bacteriophages - the order of Caudovirales - comprise the prevailing majority of known phages and are subdivided into three families based on their tail morphology. Podoviridae feature a short tail, Myoviridae a long, contractile tail and Siphoviridae a long noncontractile, flexible tail, respectively(2). The latter two possess a helical tail tube assembled around a tape measure protein that is tapered by a tail completion protein. Contractile tail tubes are furthermore environed by a sheath. These tail-structures are crucial for host-cell recognition, membrane penetration and DNA transport into the host. Recently, a high-resolution cryo-EM structure of the short fiber-less tail from the Podoviridae T7 phage was reported at a resolution of $3.3 \AA$ A.(3) Also, a cryo-EM structure of the pre-host attachment baseplate including two rings of the tail tube and sheath proteins from the Myoviridae T4 phage was solved at a resolution of 3.8-4.1 $\AA(4)$, and a cryo-EM reconstruction focused solely on the tail tube was obtained from the same images at a resolution of $3.4 \AA(5)$. Structural analysis of the tube arrangement of Siphoviridae phages was for long hindered by the variable tail bending that results from its flexibility (see Figure 1 of Tavares et al.(6)). Structural information was limited to pseudo-atomic models, which were generated for phages $\lambda(7)$ and SPP1(8) based on solution NMR structures of monomeric tail tube proteins (TTPS) and for the T5 phage by fitting X-ray structures of monomeric TTPs into a $6 \AA$ cryo-EM density $\operatorname{map}(9)$. In 2020, a cryo-EM model of the baseplate of the Staphylococcus aureus $80 \alpha$ phage was reported, which includes two rings of the tail tube that are anchored within the baseplate and are, thus, not part of the flexible tube region.(10) All models show a striking structural homology between TTPs from Myoviridae and Siphoviridae; as well as between these phage TTPs and the tube-forming proteins from other injection systems, like the bacterial type VI secretion system(11) and the extracellular injection system from bacteria and archeae(12): The tube-forming proteins share a common fold composed of two orthogonally packed $\beta$ sheets that hexamerize through the formation of an inner $\beta$-barrel that defines the lumen of the tube. However, variable elements such as loops, $\mathrm{N}$ - and $\mathrm{C}$-arms are critical to mediate intermonomer contacts driving tube assembly in these systems(7-9), and very sparse structural data are available on the position of these elements within the long-tailed phage tubes. 
In the Siphoviridae SPP1 phage, the tail tube consists of the TTPs gp17.1 and gp17.1* in a ratio of $3: 1$, with the latter being generated by a translational frameshift adding a fibronectin type III (FN3) domain to the C-terminus of the protein. However, virions only containing gp17.1 are still viable and infectious, indicating that the additional C-terminal FN3 domain is dispensable for phage assembly and infection.(13) gp17.1 monomers are unstable in solution and spontaneously self-polymerize into long tubes in vitro which are indistinguishable from native tubes. $(8,14)$ Previously, we presented the proton-detected solid-state NMR (ssNMR) assignment of deuterated, $100 \%$ back-exchanged gp17.1 tubes and deduced secondary structure information from the assigned chemical shifts, which confirmed and extended an existing homology model of a polymerized gp17.1 subunit. $(8,14)$ Additionally, we introduced new concepts based on the use of specifically labeled isoleucine-methyl groups to simplify ssNMR data, inspired by earlier progress based on methyl-labeling in solution state NMR.(15, 16). This allowed for the collection of unambiguous long-range distance restraints within and between subunits of the tail tube.(17)

However, due to the large size and inherent heterogeneity of this system the amount of data collected from these experiments does not suffice for a confident structure calculation. Therefore, we set out to expand the labeling strategy for long-range distance restraints to further methyl groups, as well as to integrate the NMR data with a 3.5 - $6 \AA$ cryo-EM map for hybrid structure calculation. Solid-state NMR is a powerful method to study the structure and dynamics(18) of insoluble proteins, such as amyloid fibrils $(19,20)$ or supramolecular assemblies(21-24). An integrated structure calculation approach(25) in combination with cryoEM has proven highly successful in previous applications by us(26) and others(27-32). The complementarity of solid-state NMR and cryo-EM can also be appreciated by work on bactofilin cytoskeletal filaments. $(33,34)$

\section{Hybrid structure calculation}

To determine the structure of the tail-tube of SPP1, we performed a hybrid structure calculation using the Inferential structure determination (ISD) approach(35) integrating data from solid-state NMR and cryo-EM simultaneously. During structure calculation only the structure of a single monomer was represented and refined. The structures of the other subunits were generated by applying symmetry operators to the subunit structure. The use of an exact symmetry is justified by the NMR data that are only consistent with a highly symmetric sample. We represented two stacked rings in the structure calculation. Each ring was composed of six subunits such that interactions between twelve subunits were considered in the structure calculation. 
a

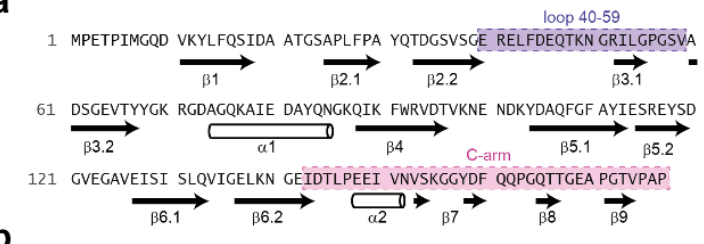

b
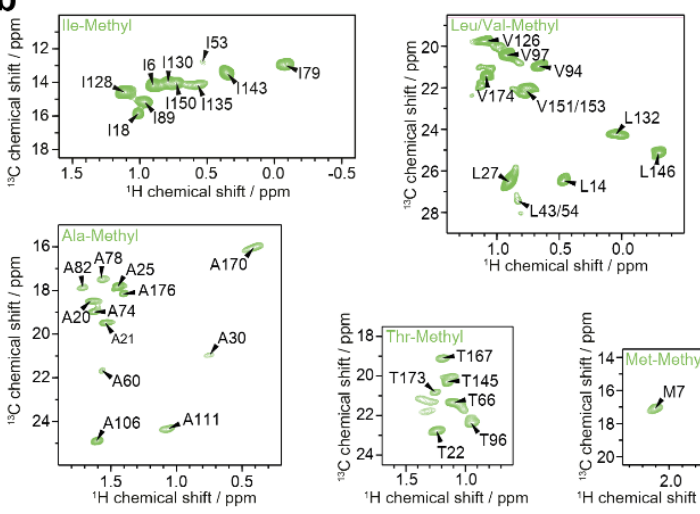

C

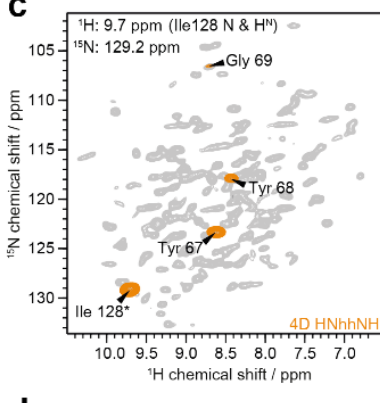

d

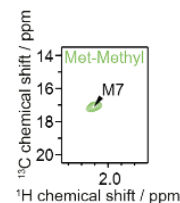

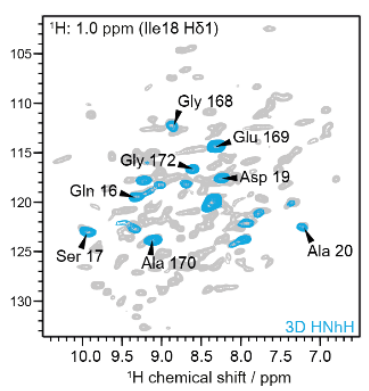

e

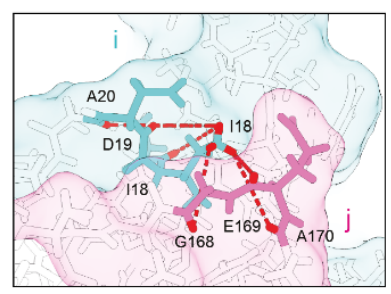

Fig. 1. Solid-state NMR data for hybrid structure calculation defines local structure. a, Backbone dihedral angles define the secondary structure. b. Isoleucine $\mathrm{C} \delta 1-$, alanine $\mathrm{C} \beta$-, leucine/valine $\mathrm{C} \delta / \mathrm{C} \gamma$-, threonine $\mathrm{C} \gamma 2-$, and methionine $\mathrm{C}_{\varepsilon}$-methyl labeling renders those moieties "NMR-visible" and yields highly resolved NMR spectra. c, Long-range restraints between amide protons are extracted from a $4 \mathrm{D} \mathrm{HNhhNH}$ spectrum, whereas long-range restraints between amide and methyl groups are extracted from a series of 3D HNhH spectra. 2D planes from both types of spectra are superimposed on a 2D hNH fingerprint spectrum (grey). d, Representative long-range restraints defining the inner $\beta$-barrel of the tail tube. The colored $\beta$-strands belong to one monomer, whereas the grey $\beta$ strands are from the neighboring subunits. Amide-amide contacts are highlighted in violet, amide-methyl contacts in cyan. e, Schematic representation of long-range distance restraints between the C $\delta 1$ methyl group of lle 18 and amide groups, defining the interface between the $\mathrm{N}$-terminus of one monomer $\mathrm{i}$ (including lle18; in cyan) and the Carm (143-176) of another monomer $j$ (in pink) within the tail tube. Protons are colored in red.

For the collection of solid-state NMR long-range distance restraints, we overexpressed a set of differently labeled TTP gp17.1 in E. coli, purified them, and let them self-polymerize into native-like tail tubes as detailed in the Methods. Torsion angles were predicted based on assigned backbone chemical shifts (Figure 1a). Specific precursor molecules were supplemented during protein expression in deuterated media, introducing NMR visible methyl groups within certain amino acids of gp17.1 (Figure 1b). We produced samples that were homogeneously methyl and ${ }^{15} \mathrm{~N}$ labeled, as well as samples that were heterogeneous mixtures of $50 \%$ methyl-labeled and $50 \%{ }^{15} \mathrm{~N}$ labeled subunits. The latter samples were used to detect intermolecular interfaces, as previously described by us.(17) All eleven investigated methyllabeled and/or deuterated samples and their precursors are listed in Table S1. 4D and 3D proton-detected ssNMR experiments at $40 \mathrm{kHz}$ magic-angle spinning (MAS) and $900 \mathrm{MHz}$ proton Larmor frequency were used to probe long-range distance restraints between the following: 1.) amide groups (Figure 1c, left panel)(36, 37); 2.) methyl groups; 3.) methyl and amide groups globally (Figure 1c, right panel); 4.) methyl and amide groups at protein-protein interfaces. All of these experiments generated highly unambiguous restraints due to their highdimensionality (4D) or spectral simplicity (amino-acid specific methyl labeling) - as visualized in Figure 1d where a set of consistent restraints (amide-amide and methyl-amide contacts) defines the inner $\beta$-barrel motif of the tail tube formed by the $\beta$-strands $\beta 2.2, \beta 3.2, \beta 6.1$ and 35.2. In mixed labeled samples (as detailed in Table S1) magnetization transfer between methyl and amide groups is solely possible at protein-protein interfaces. Hence, these samples deliver a set of restraints that defines the organization of gp17.1 subunits within the tube. Figure 1e shows an exemplary protein interface between the $\mathrm{N}$-terminus of a subunit, including the lle18 labeled methyl group, and the C-terminus of another subunit. 
a

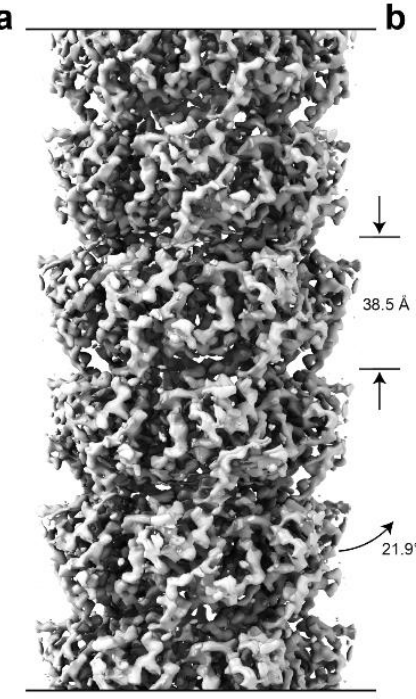

b

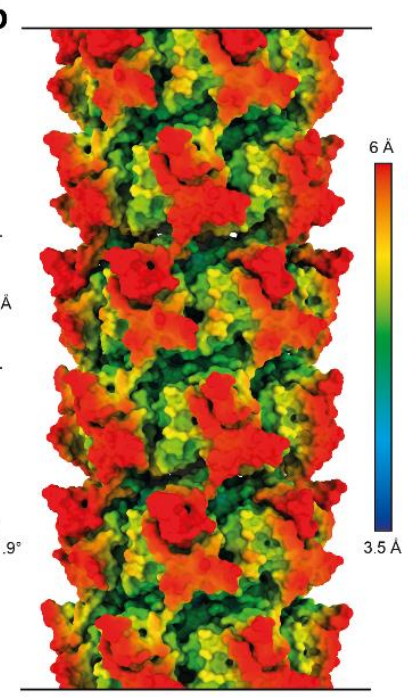

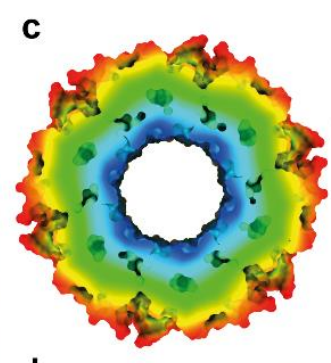

d

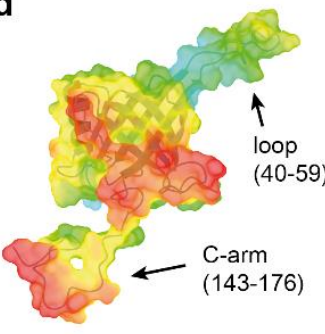

e

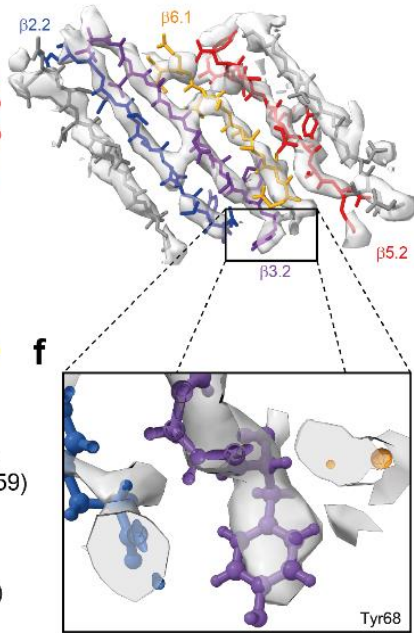

Fig. 2. Cryo-EM data for hybrid structure calculation provides global and local information. a, 3.5 - 6 A cryo-EM map of the tail tube of SPP1 consisting of polymerized gp17.1 subunits does not only allow to deduce symmetry restraints but also limits the position of all atoms within the density. $\mathbf{b}-\mathbf{d}$, Local resolution of the cryo-EM map increases going from outer to the inner surface of the tail tube. $\mathbf{e}$, The inner region of the map reveals a highly resolved $\beta$-barrel and allows for the positioning of bulky sidechains as exemplified for Tyr68 (f).

For cryo-EM experiments, we purified $\Delta \mathrm{N}-3$ gp17.1 which is indistinguishable from wt gp17.1 as judged by solid-state NMR (See Figure S1). Curvy tubes were observed in the micrographs (Figure S2). For image processing those tubes that appeared most straight were selected. 3D reconstruction (see Methods) yielded a density map with an average resolution of $4 \AA$ (Figure $2 a$ ). The local resolution varies significantly (Figure $2 b-d$ ), from about $3.5 \AA$ at the inner ring where the $\beta$-strands are well resolved (Figure $2 \mathrm{e}-\mathrm{f}$ ), to worse than $5 \AA$ at the periphery.

\section{Overall structure of the SPP1 tail tube}

Figure 3 shows the structure of the tail-tube of gp17.1 as determined by hybrid structure calculation (see also Movie S1 and Figure S3) with a heavy atom RMSD of $1.8 \pm 0.9 \AA$ (Backbone RMSD of $1.1 \pm 0.5 \AA$ ) over the entire protein sequence. The monomer of gp17.1 forms a central $\beta$-sandwich-type fold consisting of eight $\beta$-strands. This fold is flanked by an $\alpha$ helix (74-86) and loop regions, of which the long C-terminal arm (C-arm, 143-176) stands out (Figure 3a). Six gp17.1 subunits assemble into a ring with the inner $24 \beta$-strands forming a $\beta$ barrel that defines the inner lumen of the tube. This inner lumen exhibits a negative electrostatic potential (see Figure S4) which facilitates sliding of the viral DNA through the tube by repelling it from the surface. Additionally, inner ring contacts are mediated by the large loop region 40-59. The $\alpha$-helices are arranged almost parallel to the tail tube axis (Figure 3b). These rings stack onto each other with a rotation of $21.9^{\circ}$ forming a right-handed helical, hollow tube (Figure 3c). The surface of one gp17.1 subunit features a hydrophobic patch that is shaped by sidechains of various hydrophobic amino acids (Figure $3 \mathrm{~d}$ ). In the context of the tail tube complex the C-arm of the superjacent subunit folds onto the outer $\beta$-sheet of the $\beta$-sandwich fold by anchoring the sidechain of Gln162 into a pocket (Figure 3e). This interaction obscures the lipophilic area whereupon the complex is stabilized, because the number of unfavorable hydrophobic contacts with the solvent is reduced (Figure 3f). This explains why a previously reported C-terminally truncated mutant of gp17.1 remains monomeric(17). Additional ring-to- 
bioRxiv preprint doi: https://doi.org/10.1101/2020.06.23.166439; this version posted June 23,2020 . The copyright holder for this preprint (which was not certified by peer review) is the author/funder, who has granted bioRxiv a license to display the preprint in perpetuity. It is made available under aCC-BY-NC-ND 4.0 International license.

ring contacts are mediated by the loop region 40-59 which interacts with five neighboring subunits - mostly by establishing electrostatic contacts (Figure $3 \mathrm{~g}$ ).
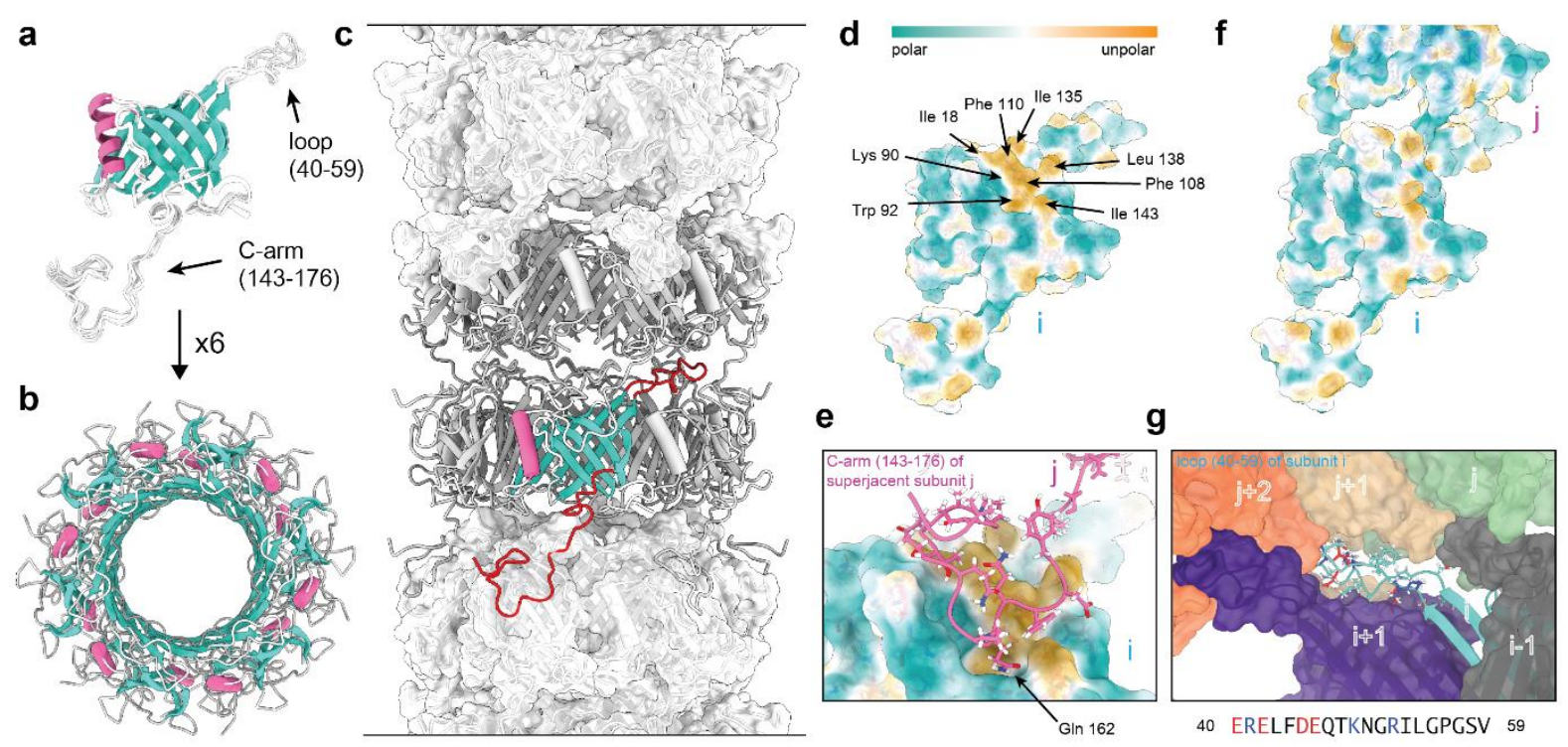

Fig. 3. Structure of polymerized gp17.1 forming the tail tube of the bacteriophage SPP1. a, Final ten lowest-energy structures of a gp17.1 subunit which consist of a central $\beta$-sandwich-type fold that is flanked by an $\alpha$-helix, a large loop and an extended C-terminal arm (C-arm). b. Six gp17.1 monomers form a hexameric ring. The inner $\beta$-sheets of the $\beta$-sandwiches organize in a $\beta$-barrel motif that forms the lumen of the tube. c, These hexameric rings stack onto each other in a helical fashion creating a hollow tube. Ring-to-ring contacts are mediated by the two loop regions (highlighted in red) - especially by the C-arm that folds onto the subjacent ring. $\mathbf{d}$, The molecular lipophilicity potential of gp17.1 reveals a hydrophobic patch on the surface of one subunit i. e-f, This unpolar area is obscured by the C-arm of the superjacent subunit $\mathrm{j}$ within the complex of the tail-tube - by anchoring the sidechain of Gln 162 into a pocket. $\mathbf{g}$, The loop of subunit i features mostly electrostatic interactions with five neighboring subunits within the complex. Charged amino acids are colored in red (negative) and blue (positive).

Structural alignments of gp17.1 and existing TTP structures of other systems show high similarity as expected (Figure S5) - all featuring hexameric, helically stacked rings with subunits consisting of a $\beta$-sandwich-type fold and one parallel $\alpha$-helix. Loop 40-59 is also present at the interface between subunits in the phages $80 \alpha(10)$ and T4(5), suggesting that it is a conserved structural element across both Siphoviridae and Myoviridae families. The mentioned C-arm is not observed in the Myoviridae T4, however it is present in $80 \alpha(10)$ (even if not completely resolved). It might be a critical element regulating the tail structure in a subgroup of Siphoviridae. The Myoviridae T4(5) phage TTP gp19 features two additional linkers that mediate intermolecular interactions - which facilitates contact to 10 different subunits over an area of $6706 \AA^{2}$ within the tail tube. gp17.1, however, only interconnects with 6 different subunits over $4850 \AA^{2}$. This dramatically reduced contact - in addition to not being bundled in a sheath - is expected to enable flexibility of this Siphoviridae tail tube.

\section{Dynamic regions mediate tail bending}

To determine the driving forces contributing to the flexibility of the tail tube of SPP1, we created a model of a bent tail tube based on the structure of monomeric gp17.1 and 2D class averages of bent tubes as detailed in the Methods. As shown in Figure 4a (and Movie S2), most structural changes during the bending process happen on the outer edge of the curve. This suggests that the bending of the tube is facilitated by stretching of certain linker regions 
(as opposed to compression). The hinge regions required for the structural reorganization from a straight to a bent state (Figure $4 \mathrm{~b}$ ) match regions in the cryo-EM density with pronounced variances (Figure 4c). These areas comprise regions forming inter-ring contacts - especially the C-arm (143-176), its binding interface on the subjacent subunit and the loop (40-59).

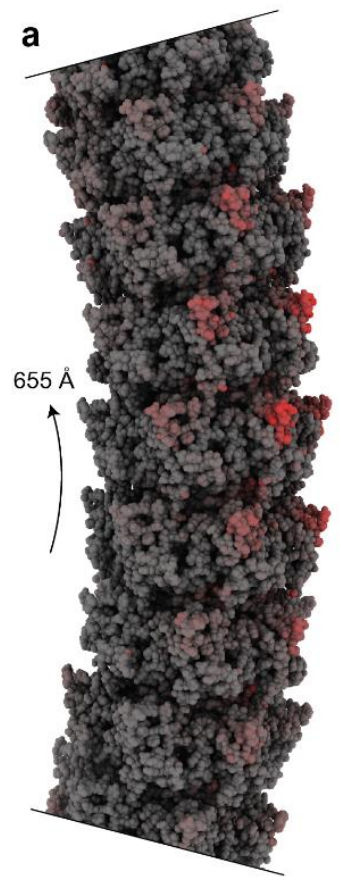

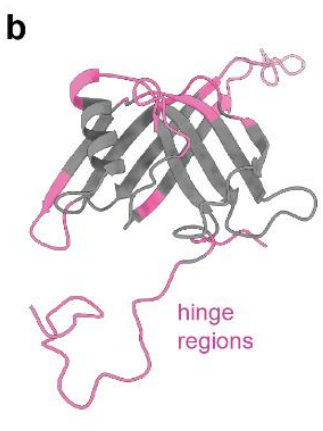

e

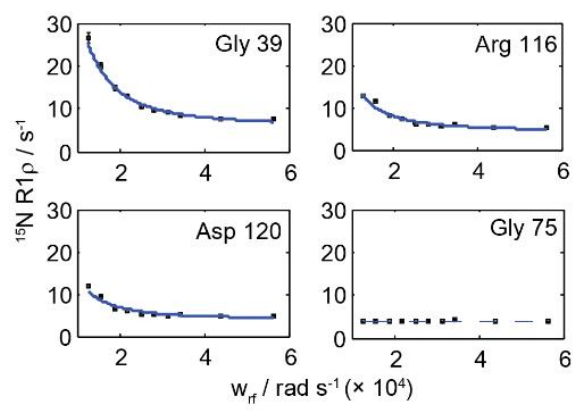

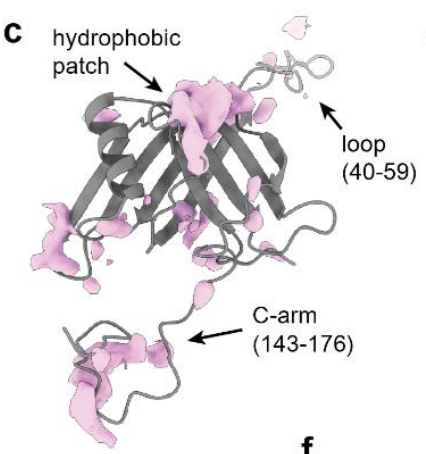
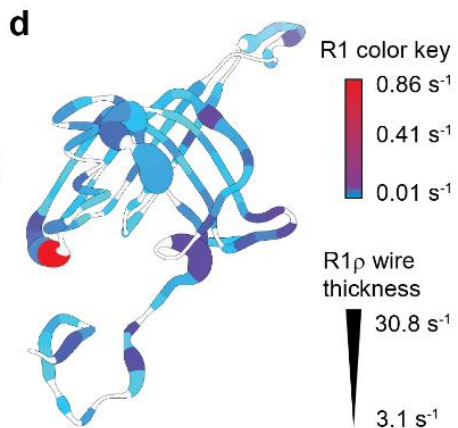

$\mathbf{f}$

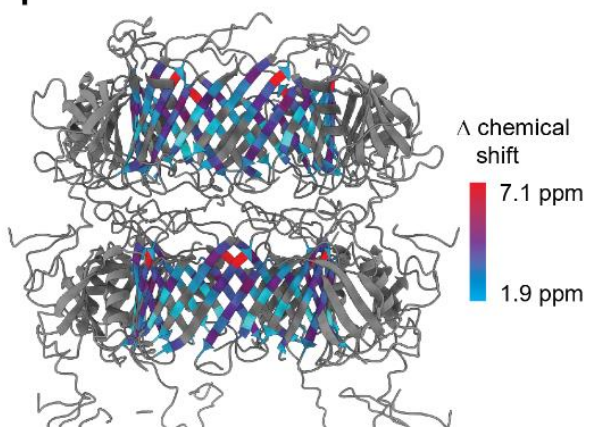

Fig. 4. Bending of the tail tube is mediated by flexible hinge regions. a, Model of a bent SPP1 tail tube with a curvature radius of $655 \AA$. The model is based on the structure of straight tubes and 2D class averages of bent tubes. Most structural changes are found on the outside of the curve (red) which implies that the bending process is mediated by stretching. $\mathbf{b}$, Regions that act as hinges during bending of the tube are colored in pink. $\mathbf{c}$, Variances in the cryo-EM map (pink) match the hinge regions. $\mathbf{d}$, Also, hinge regions are associated with highest ${ }^{15} \mathrm{~N} \mathrm{R}_{1}$ (color key) and $R_{1 \rho}$ (thickness of wire) relaxation rates. White coloring represents missing values. e, Decaying relaxation dispersion profiles indicate the presence of slow motions. $\mathbf{f}$, Relaxation dispersion profiles of the inner $\beta$-barrel can be fitted in a correlated manner to a two-state exchange process. Smallest chemical shift changes correlate with middle regions of the $\beta$-barrel which are furthest away from the hinge regions (color key).

Additionally, we analyzed ${ }^{15} \mathrm{~N} \mathrm{R}_{1}$ and ${ }^{15} \mathrm{~N} \mathrm{R}_{1 \rho}$ relaxation rates of fully polymerized gp17.1 by solid-state NMR as detailed in the Methods (Figure S6). $R_{1}$ relaxation rates are sensitive to motions on the nanosecond timescale, whereas $R_{1 \rho}$ rates report on motions on the nanosecond to millisecond timescale.(38) Figure 4d shows both values mapped onto a gp17.1 subunit within the tail complex. The inner $\beta$-barrel shows nearly no motion on these timescales - which correlates with these areas being highest resolved in the cryo-EM density. On the opposite, the hinge regions are associated with the highest relaxation rates, demonstrating that these areas are highly dynamic. Furthermore, we investigated ${ }^{15} \mathrm{~N}$ relaxation dispersion which is sensitive to motions on the millisecond timescale (Figure S7-S9). Figure 4e shows representative ${ }^{15} \mathrm{~N}$ relaxation dispersion curves; flat profiles indicate the absence of motion, whereas decaying profiles indicate the presence of dynamics. Most residues are involved in slow motions (Figure S10). However, only residues belonging to the $\beta$-barrel can be fitted in a combined approach to a two-state model indicating the existence of two distinct conformations of the $\beta$-barrel (Figure 4f). Calculated chemical shift differences between both states are higher for residues in proximity to the hinge regions. Thus, we propose that these two states could represent the two extrema of tube bending - either lying on the inside or the outside of the 
curve. The global, collective nature of this motion does not impose heterogeneity onto the cryoEM map since only straight tubes are considered for structure calculation.

Overall, our hybrid data support a model where the C-arm (143-176) and the loop (4059) act as bellows contributing to tail tube bending by stretching. Our dynamic structure of the tail tube is reminiscent of a molecular spinal column. The hexameric rings forming the inner $\beta-$ barrel would be in this picture the vertebrae, while the flexible parts ( $\mathrm{C}$-arm and loop) correspond to the intervertebral discs. The flexibility of the system might facilitate the screening of the bacterial membrane to find the receptor for infection initiation. We expect that the combination of sophisticated ssNMR experiments and cryo-EM will help to characterize structures of other dynamic and/or flexible supramolecular assemblies, in particular those systems where the conformational flexibility leads to a lack of resolution in cryo-EM reconstructions - while depending on the timescale of these dynamics the quality of NMR spectra may not be affected.

\section{References and Notes:}

1. R. M. Dedrick, C. A. Guerrero-Bustamante, R. A. Garlena, D. A. Russell, K. Ford, K. Harris, K. C. Gilmour, J. Soothill, D. Jacobs-Sera, R. T. Schooley, G. F. Hatfull, H. Spencer, Engineered bacteriophages for treatment of a patient with a disseminated drug-resistant Mycobacterium abscessus. Nat. Med. 25, 730-733 (2019).

2. H.-W. Ackermann, Bacteriophage observations and evolution. Res. Microbiol. 154, 245-251 (2003).

3. A. Cuervo, M. Fàbrega-Ferrer, C. Machón, J. J. Conesa, F. J. Fernández, R. PérezLuque, M. Pérez-Ruiz, J. Pous, M. C. Vega, J. L. Carrascosa, M. Coll, Structures of T7 bacteriophage portal and tail suggest a viral DNA retention and ejection mechanism. Nat. Commun. 10, 1-11 (2019).

4. N. M. I. Taylor, N. S. Prokhorov, R. C. Guerrero-Ferreira, M. M. Shneider, C. Browning, K. N. Goldie, H. Stahlberg, P. G. Leiman, Structure of the T4 baseplate and its function in triggering sheath contraction. Nature. 533, 346-352 (2016).

5. W. Zheng, F. Wang, N. M. I. Taylor, R. C. Guerrero-Ferreira, P. G. Leiman, E. H. Egelman, Refined Cryo-EM Structure of the T4 Tail Tube: Exploring the Lowest Dose Limit. Structure. 25, 1436-1441.e2 (2017).

6. P. Tavares, A. Dröge, R. Lurz, I. Graeber, E. Orlova, P. Dube, M. van Heel, The SPP1 connection. FEMS Microbiol. Rev. 17, 47-56 (1995).

7. L. G. Pell, V. Kanelis, L. W. Donaldson, P. Lynne Howell, A. R. Davidson, The phage $\lambda$ major tail protein structure reveals a common evolution for long-tailed phages and the type VI bacterial secretion system. Proc. Natl. Acad. Sci. 106, 4160-4165 (2009).

8. C. Langlois, S. Ramboarina, A. Cukkemane, I. Auzat, B. Chagot, B. Gilquin, A. Ignatiou, I. Petitpas, E. Kasotakis, M. Paternostre, H. E. White, E. V. Orlova, M. Baldus, P. Tavares, S. Zinn-Justin, Bacteriophage SPP1 tail tube protein selfassembles into $\beta$-structure rich tubes. J. Biol. Chem. 290, 3836-3849 (2014).

9. C. A. Arnaud, G. Effantin, C. Vivès, S. Engilberge, M. Bacia, P. Boulanger, E. Girard, G. Schoehn, C. Breyton, Bacteriophage T5 tail tube structure suggests a trigger mechanism for Siphoviridae DNA ejection. Nat. Commun. 8, 1-9 (2017).

10. J. L. Kizziah, K. A. Manning, A. D. Dearborn, T. Dokland, Structure of the host cell recognition and penetration machinery of a Staphylococcus aureus bacteriophage. PLoS Pathog. 16 (2020), doi:10.1371/journal.ppat.1008314. 
bioRxiv preprint doi: https://doi.org/10.1101/2020.06.23.166439; this version posted June 23, 2020. The copyright holder for this preprint (which was not certified by peer review) is the author/funder, who has granted bioRxiv a license to display the preprint in perpetuity. It is made available under aCC-BY-NC-ND 4.0 International license.

11. J. Wang, M. Brackmann, D. Castaño-Díez, M. Kudryashev, K. N. Goldie, T. Maier, H. Stahlberg, M. Basler, Cryo-EM structure of the extended type VI secretion system sheath-tube complex. Nat. Microbiol. 2, 1507-1512 (2017).

12. F. Jiang, N. Li, X. Wang, J. Cheng, Y. Huang, Y. Yang, J. Yang, B. Cai, Y. P. Wang, Q. Jin, N. Gao, Cryo-EM Structure and Assembly of an Extracellular Contractile Injection System. Cell. 177, 370-383.e15 (2019).

13. I. Auzat, A. Dröge, F. Weise, R. Lurz, P. Tavares, Origin and function of the two major tail proteins of bacteriophage SPP1. Mol. Microbiol. 70, 557-569 (2008).

14. M. Zinke, P. Fricke, C. Samson, S. Hwang, J. S. Wall, S. Lange, S. Zinn-Justin, A. Lange, Bacteriophage tail-tube assembly studied by proton-detected 4D solid-state NMR. Angew. Chemie Int. Ed., 1-6 (2017).

15. R. Sprangers, A. Velyvis, L. E. Kay, Solution NMR of supramolecular complexes: Providing new insights into function. Nat. Methods. 4, 697-703 (2007).

16. Y. Jiang, P. Rossi, C. G. Kalodimos, Structural basis for client recognition and activity of Hsp40 chaperones. Science. 365, 1313-1319 (2019).

17. M. Zinke, P. Fricke, S. Lange, S. Zinn-Justin, A. Lange, Protein-Protein Interfaces Probed by Methyl Labeling and Proton-Detected Solid-State NMR Spectroscopy. ChemPhysChem, 1-5 (2018).

18. C. M. Quinn, M. Wang, M. P. Fritz, B. Runge, J. Ahn, C. Xu, J. R. Perilla, A. M. Gronenborn, T. Polenova, Dynamic regulation of HIV-1 capsid interaction with the restriction factor TRIM5a identified by magic-angle spinning NMR and molecular dynamics simulations. Proc. Natl. Acad. Sci. U. S. A. 115, 11519-11524 (2018).

19. M. T. Colvin, R. Silvers, Q. Z. Ni, T. V. Can, I. Sergeyev, M. Rosay, K. J. Donovan, B. Michael, J. Wall, S. Linse, R. G. Griffin, Atomic Resolution Structure of Monomorphic Aß42 Amyloid Fibrils. J. Am. Chem. Soc. 138, 9663-9674 (2016).

20. H. Van Melckebeke, C. Wasmer, A. Lange, E. Ab, A. Loquet, A. Böckmann, B. H. Meier, Atomic-resolution three-dimensional structure of HET-s(218-289) amyloid fibrils by solid-state nmr spectroscopy. J. Am. Chem. Soc. 132, 13765-13775 (2010).

21. D. T. Murray, M. Kato, Y. Lin, K. R. Thurber, I. Hung, S. L. Mcknight, R. Tycko, D. T. Murray, M. Kato, Y. Lin, K. R. Thurber, I. Hung, S. L. Mcknight, R. Tycko, Structure of FUS Protein Fibrils and Its Relevance to Self-Assembly and Phase Separation of LowArticle Structure of FUS Protein Fibrils and Its Relevance to Self-Assembly and Phase Separation of Low-Complexity Domains, 615-627 (2017).

22. H. Fraga, C. A. Arnaud, D. F. Gauto, M. Audin, V. Kurauskas, P. Macek, C. Krichel, J. Y. Guan, J. Boisbouvier, R. Sprangers, C. Breyton, P. Schanda, Solid-state NMR H$\mathrm{N}-(\mathrm{C})-\mathrm{H}$ and $\mathrm{H}-\mathrm{N}-\mathrm{C}-\mathrm{C} 3 \mathrm{D} / 4 \mathrm{D}$ correlation experiments for resonance assignment of large proteins. ChemPhysChem. 18, 2697-2703 (2017).

23. A. Goldbourt, Structural characterization of bacteriophage viruses by NMR. Prog. Nucl. Magn. Reson. Spectrosc. 114-115, 192-210 (2019).

24. J. L. Lorieau, L. A. Day, A. E. McDermott, Conformational dynamics of an intact virus: Order parameters for the coat protein of Pf1 bacteriophage. Proc. Natl. Acad. Sci. U. S. A. 105, 10366-10371 (2008).

25. S. J. Ganesan, M. J. Feyder, I. E. Chemmama, F. Fang, M. P. Rout, B. T. Chait, Y. Shi, M. Munson, A. Sali, Integrative Structure and Function of the Yeast Exocyst Complex. Protein Sci. (2020), doi:10.1002/pro.3863.

26. J. P. Demers, B. Habenstein, A. Loquet, S. Kumar Vasa, K. Giller, S. Becker, D. 
bioRxiv preprint doi: https:/doi.org/10.1101/2020.06.23.166439. this version posted June 23, 2020. The copyright holder for this preprint (which was not certified by peer review) is the author/funder, who has granted bioRxiv a license to display the preprint in perpetuity. It is made available under aCC-BY-NC-ND 4.0 International license.

Baker, A. Lange, N. G. Sgourakis, High-resolution structure of the Shigella type-III secretion needle by solid-state NMR and cryo-electron microscopy. Nat. Commun. 5, $1-12(2014)$.

27. D. F. Gauto, L. F. Estrozi, C. D. Schwieters, G. Effantin, P. Macek, R. Sounier, A. C. Sivertsen, E. Schmidt, R. Kerfah, G. Mas, J. P. Colletier, P. Güntert, A. Favier, G. Schoehn, P. Schanda, J. Boisbouvier, Integrated NMR and cryo-EM atomic-resolution structure determination of a half-megadalton enzyme complex. Nat. Commun. 10, 112 (2019).

28. M. G. ladanza, R. Silvers, J. Boardman, H. I. Smith, T. K. Karamanos, G. T. Debelouchina, Y. Su, R. G. Griffin, N. A. Ranson, S. E. Radford, The structure of a $32-$ microglobulin fibril suggests a molecular basis for its amyloid polymorphism. Nat. Commun. 9 (2018), doi:10.1038/s41467-018-06761-6.

29. L. Sborgi, F. Ravotti, V. P. Dandey, M. S. Dick, A. Mazur, S. Reckel, M. Chami, S. Scherer, M. Huber, A. Böckmann, E. H. Egelman, H. Stahlberg, P. Broz, B. H. Meier, S. Hiller, Structure and assembly of the mouse ASC inflammasome by combined NMR spectroscopy and cryo-electron microscopy. Proc. Natl. Acad. Sci. U. S. A. 112, 13237-13242 (2015).

30. L. Gremer, D. Schölzel, C. Schenk, E. Reinartz, J. Labahn, R. B. G. Ravelli, M. Tusche, C. Lopez-iglesias, W. Hoyer, H. Heise, D. Willbold, G. F. Schröder, Fibril structure of amyloid-beta(1-42) by cryo - electron microscopy. Science.. 358, 116-119 (2017).

31. B. Bardiaux, G. C. de Amorim, A. Luna Rico, W. Zheng, I. Guilvout, C. Jollivet, M. Nilges, E. H. Egelman, N. Izadi-Pruneyre, O. Francetic, Structure and Assembly of the Enterohemorrhagic Escherichia coli Type 4 Pilus. Structure. 27, 1082-1093.e5 (2019).

32. R. Guerrero-Ferreira, N. M. I. Taylor, A. A. Arteni, P. Kumari, D. Mona, P. Ringler, M. Britschgi, M. E. Lauer, A. Makky, J. Verasdock, R. Riek, R. Melki, B. H. Meier, A. Böckmann, L. Bousset, H. Stahlberg, Two new polymorphic structures of human fulllength alpha-synuclein fibrils solved by cryo-electron microscopy. Elife. 8, 1-24 (2019).

33. C. Shi, P. Fricke, L. Lin, V. Chevelkov, M. Wegstroth, K. Giller, S. Becker, M. Thanbichler, A. Lange, Atomic-resolution structure of cytoskeletal bactofilin by solidstate NMR. Sci. Adv. 1, e1501087 (2015).

34. X. Deng, A. Gonzalez Llamazares, J. M. Wagstaff, V. L. Hale, G. Cannone, S. H. McLaughlin, D. Kureisaite-Ciziene, J. Löwe, The structure of bactofilin filaments reveals their mode of membrane binding and lack of polarity. Nat. Microbiol. 4, 23572368 (2019).

35. W. Rieping, M. Habeck, M. Nilges, Biochemistry: Inferential structure determination. Science. 309, 303-306 (2005).

36. M. Huber, S. Hiller, P. Schanda, M. Ernst, A. Böckmann, R. Verel, B. H. Meier, A proton-detected 4D solid-state NMR experiment for protein structure determination. Chemphyschem. 12, 915-918 (2011).

37. R. Linser, B. Bardiaux, V. Higman, U. Fink, B. Reif, Structure calculation from unambiguous long-range amide and methyl $1 \mathrm{H}-1 \mathrm{H}$ distance restraints for a microcrystalline protein with MAS solid-state NMR spectroscopy. J. Am. Chem. Soc. 133, 5905-5912 (2011).

38. P. Schanda, M. Ernst, Studying dynamics by magic-angle spinning solid-state NMR spectroscopy: Principles and applications to biomolecules. Prog. Nucl. Magn. Reson. Spectrosc. 96, 1-46 (2016).

39. T. J. Stevens, R. H. Fogh, W. Boucher, V. A. Higman, F. Eisenmenger, B. Bardiaux, B. 
J. Van Rossum, H. Oschkinat, E. D. Laue, A software framework for analysing solidstate MAS NMR data. J. Biomol. NMR. 51, 437-447 (2011).

40. O. Trott, A. G. Palmer, R1 $\rho$ relaxation outside of the fast-exchange limit. J. Magn. Reson. 154, 157-160 (2002).

41. C. Öster, S. Kosol, J. R. Lewandowski, Quantifying Microsecond Exchange in Large Protein Complexes with Accelerated Relaxation Dispersion Experiments in the Solid State. Sci. Rep. 9, 1-10 (2019).

42. S. Q. Zheng, E. Palovcak, J. P. Armache, K. A. Verba, Y. Cheng, D. A. Agard, MotionCor2: Anisotropic correction of beam-induced motion for improved cryo-electron microscopy. Nat. Methods. 14, 331-332 (2017).

43. K. Zhang, Gctf: Real-time CTF determination and correction. J. Struct. Biol. 193, 1-12 (2016).

44. S. H. W. Scheres, RELION: Implementation of a Bayesian approach to cryo-EM structure determination. J. Struct. Biol. 180, 519-530 (2012).

45. B. Habenstein, A. Loquet, S. Hwang, K. Giller, S. K. Vasa, S. Becker, M. Habeck, A. Lange, Hybrid Structure of the Type 1 Pilus of Uropathogenic Escherichia coli. Angew. Chemie - Int. Ed. 54, 11691-11695 (2015).

46. M. Habeck, Bayesian modeling of biomolecular assemblies with cryo-EM maps. Front. Mol. Biosci. 4 (2017), doi:10.3389/fmolb.2017.00015.

47. P. Emsley, B. Lohkamp, W. G. Scott, K. Cowtan, Features and development of Coot. Acta Crystallogr. Sect. D Biol. Crystallogr. 66, 486-501 (2010).

48. D. Liebschner, P. V. Afonine, M. L. Baker, G. Bunkoczi, V. B. Chen, T. I. Croll, B. Hintze, L. W. Hung, S. Jain, A. J. McCoy, N. W. Moriarty, R. D. Oeffner, B. K. Poon, M. G. Prisant, R. J. Read, J. S. Richardson, D. C. Richardson, M. D. Sammito, O. V. Sobolev, D. H. Stockwell, T. C. Terwilliger, A. G. Urzhumtsev, L. L. Videau, C. J. Williams, P. D. Adams, Macromolecular structure determination using X-rays, neutrons and electrons: Recent developments in Phenix. Acta Crystallogr. Sect. $D$ Struct. Biol. 75, 861-877 (2019).

49. Z. Wang, G. F. Schröder, Real-space refinement with DireX: From global fitting to side-chain improvements. Biopolymers. 97, 687-697 (2012).

50. T. D. Goddard, C. C. Huang, E. C. Meng, E. F. Pettersen, G. S. Couch, J. H. Morris, T. E. Ferrin, UCSF ChimeraX: Meeting modern challenges in visualization and analysis. Protein Sci. 27, 14-25 (2018).

51. W. G. Krebs, M. Gernstein, The morph server: a standardized system for analyzing and visualizing macromolecular motions in a database framework. Nucleic Acids Res. 28, 1665-1675 (2000).

52. T. J. Dolinsky, J. E. Nielsen, J. A. McCammon, N. A. Baker, PDB2PQR: An automated pipeline for the setup of Poisson-Boltzmann electrostatics calculations. Nucleic Acids Res. 32, 665-667 (2004).

53. N. A. Baker, D. Sept, S. Joseph, M. J. Holst, J. A. McCammon, Electrostatics of nanosystems: Application to microtubules and the ribosome. Proc. Natl. Acad. Sci. U. S. A. 98, 10037-10041 (2001).

54. W. Zheng, F. Wang, N. M. I. Taylor, R. C. Guerrero-Ferreira, P. G. Leiman, E. H. Egelman, Refined Cryo-EM Structure of the T4 Tail Tube: Exploring the Lowest Dose Limit. Structure. 25, 1436-1441.e2 (2017).

55. K. H. Gardner, L. E. Kay, Production and incorporation of $15 \mathrm{~N}, 13 \mathrm{C}, 2 \mathrm{H}(1 \mathrm{H}-\delta 1$ 
methyl) isoleucine into proteins for multidimensional NMR studies. J. Am. Chem. Soc. 119, 7599-7600 (1997).

56. I. Ayala, R. Sounier, N. Usé, P. Gans, J. Boisbouvier, An efficient protocol for the complete incorporation of methyl-protonated alanine in perdeuterated protein. $J$. Biomol. NMR. 43, 111-119 (2009).

57. P. Gans, O. Hamelin, R. Sounier, I. Ayala, M. A. Durá, C. D. Amero, M. NoirclercSavoye, B. Franzetti, M. J. Plevin, J. Boisbouvier, Stereospecific isotopic labeling of methyl groups for NMR spectroscopic studies of high-molecular-weight proteins. Angew. Chemie - Int. Ed. 49, 1958-1962 (2010).

58. A. Velyvis, A. M. Ruschak, L. E. Kay, An Economical Method for Production of 2H,13CH3-Threonine for Solution NMR Studies of Large Protein Complexes: Application to the $670 \mathrm{kDa}$ Proteasome. PLoS One. 7, 1-8 (2012).

59. M. Fischer, K. Kloiber, J. Häusler, K. Ledolter, R. Konrat, W. Schmid, Synthesis of a13C-methyl-group-labeled methionine precursor as a useful tool for simplifying protein structural analysis by NMR spectroscopy. ChemBioChem. 8, 610-612 (2007).

60. R. Kerfah, O. Hamelin, J. Boisbouvier, D. Marion, CH3-specific NMR assignment of alanine, isoleucine, leucine and valine methyl groups in high molecular weight proteins using a single sample. J. Biomol. NMR. 63, 389-402 (2015).

61. S. G. Hyberts, A. G. Milbradt, A. B. Wagner, H. Arthanari, G. Wagner, Application of iterative soft thresholding for fast reconstruction of NMR data non-uniformly sampled with multidimensional Poisson Gap scheduling. J. Biomol. NMR. 52, 315-327 (2012).

\section{Acknowledgements}

We thank Dr. Paulo Tavares for valuable discussions and Dr. Sascha Lange for help with the sample production. Molecular graphics and analyses were performed with UCSF ChimeraX, developed by the Resource for Biocomputing, Visualization, and Informatics at the University of California, San Francisco, with support from National Institutes of Health R01-GM129325 and the Office of Cyber Infrastructure and Computational Biology, National Institute of Allergy and Infectious Diseases.

\section{Funding}

This work was supported by the Leibniz-Forschungsinstitut für Molekulare Pharmakologie (FMP) and the European Research Council (ERC Starting Grant to A.L.). C.Ö. was supported by the Human Frontier Science Program LT000303/2019-L. M.H. was supported by Deutsche Forschungsgemeinschaft (DFG) via project B09 (SFB 860).

\section{Author contributions}

M.Z. produced samples for NMR and cryo-EM measurements and performed solidstate NMR measurements. M.Z., S.Z.-J., and A.L. analyzed data from solid-state NMR measurements. C.O. and M.Z. analyzed the relaxation data. K.A.A.S., R.R., and G.F.S. performed cryo-EM measurements, K.A.A.S. and G.F.S. analyzed cryo-EM data, M.H. performed the hybrid structure calculation, A.L., M.H., and G.F.S. conceived this study, M.Z., G.F.S., M.H., and A.L. wrote the manuscript. 


\section{Competing interests}

The authors declare no competing interests.

\section{Data and materials availability}

Solid-state NMR chemical shift assignment is deposited at the Biological Magnetic Resonance Data Bank under the accession code 27468. Cryo EM electron density map is deposited at the Electron Microscopy Data Bank under the accession code EMD-10792. Protein structures are deposited at the Protein Data Bank under the accession codes 6YEG (Hybrid structure of the SPP1 tail tube by solid-state NMR and cryo EM - Final EM Refinement) and 6YQ5 (Hybrid structure of the SPP1 tail tube by solid-state NMR and cryo EM - NMR ensemble).

\section{Supplementary Materials:}

Materials and Methods

Figures S1-S13

Tables S1-S11

Movies S1-S2

References (39-61) 